\title{
HUBUNGAN PENGETAHUAN DAN DUKUNGAN KELUARGA DENGAN KEPATUHAN KONTROL BEROBAT PASIEN SKIZOFRENIA DI POLI JIWA RSJD PROVINSI JAMBI TAHUN 2018
}

\author{
Netha Damayantie*, Rusmimpong, Elly A \\ Jurusan Keperawatan Poltekkes Kemenkes Jambi \\ * Korespondensi penulis: nethafauzi1996@gmail.com
}

\begin{abstract}
ABSTRAK
Latar Belakang: Skizofrenia seperti penyakit kejiwaan lainnya memerlukaan waktu yang lama untuk pulih. Masalah utama pada pasien paska rawat inap adalah kepatuhan kontrol atau kepatuhan dalam minum obat. Kepatuhan pasien untuk melakukan kontrol terhadap kesehatan dipengaruhi oleh pasien sendiri, dukungan keluarga, dukungan sosial dan juga dukungan petugas kesehatan. Penelitian ini bertujuan untuk mengetahui hubungan pengetahuan dan dukungan keluarga dengan kepatuhan kontrol pasien skizofrenia di Poli Jiwa RSJD Provinsi Jambi.

Metode: Penelitian ini menggunakan metode cross sectional design. Populasi pada penelitian ini adalah seluruh keluarga pasien skizofrenia di Poli Jiwa tahun 2017 yang berjumlah 11877 orang dan diambil sampel sebanyak 96 orang keluarga pasien yang melakukan kontrol yang dipilih secara accidental sampling. Instrumen penelitian berupa lembar check list kontrol ulang dan kuesioner tentang pengetahuan dan dukungan keluarga. Penelitian dilaksanakan pada bulan Juli 2018. Analisis data dilakukan secara univariat dan bivariat (Chi-square)

Hasil: Lebih dari sebagian responden tidak patuh melakukan kontrol $(58,3 \%)$, mempunyai pengetahuan kurang baik $(50 \%)$ dan memiliki dukungan keluarga positif $(52,1 \%)$ tentang kontrol ulang pasien skizofrenia. Ada hubungan antara pengetahuan keluarga dengan kepatuhan kontrol pasien skizofrenia $(p$-value $=0.00)$. Ada hubungan antara dukungan keluarga dengan kepatuhan kontrol pasien skizofrenia $(p$-value $=0.00)$

Kesimpulan: Ada hubungan antara pengetahuan dan dukungan keluarga dengan kepatuhan kontrol berobat pasien
\end{abstract} skizofrenia

Kata Kunci : kepatuhan kontrol; pengetahuan; dukungan keluarga

\author{
THE RELATIONSHIP OF KNOWLEDGE AND FAMILIY SUPPORT \\ WITH MEDICATION CONTROL COMPLIANCE OF SCHIZOPHRENIC PATIENT \\ IN RSJD JAMBI PROVINCE 2018.
}

\section{ABSTRACT}

Background: Other psychiatric illnesses such as schizophrenia need a long time to recover. The main problem in patients post hospitalization is the compliance control or compliance in taking the medication. Patient compliance to control the patient's own health is influenced by family support, social support, and also support from health workers. The aim of this study was to define the relationship of knowledge and families support with schizophrenic patient compliance control in RSJD Province Jambi.

Methods: This research used a cross sectional design to a Population of all schizophrenic patients' family in Polyclinic in 2017 totaled 11877 people, with a sample of 96 people who do control the patient's family selected by accidental sampling. Research instrument in the form of sheets of ceklist control and a questionnaire about the knowledge and support of the family. The research was carried out in July 2018. The data analysis done in a univariate and bivariat (Chi-square)

Results: The research results obtained over most respondents do not comply do control (58.3\%), has a less good knowledge (50\%) and has a positive family support (52.1\%) about the repeated control patients of schizophrenia. There is a connection between the knowledge of families with schizophrenia patient compliance control ( $p$-value $=0.00)$. There is a relationship between family support with compliance control patients of schizophrenia ( $p$-value $=0.00)$

Conclusion: There were significant relationship between the knowledge of families and family support with medication control compliance of schizophrenic patient in RSJD Jambi Province

Keyword: control compliance; knowledge; family support 


\section{PENDAHULUAN}

Skizofrenia adalah gangguan psikotik yang bersifat kronis atau kambuh ditandai dengan terdapatnya perpecahan (schism) antara pikiran, emosi dan perilaku pasien yang terkena. ${ }^{1}$ Skizofrenia tidak disebabkan oleh penyebab tunggal, tetapi dari berbagai faktor. Sebagian besar ilmuan meyakini bahwa skizofrenia adalah penyakit biologis yang disebabkan oleh faktorfaktor genetik, ketidak seimbangan kimiawi di otak, abnormalitas struktur otak, atau abnormalitas dalam lingkungan prenatal. Berbagai peristiwa stress dalam hidup dapat memberikan kontribusi pada perkembangan skizofrenia pada mereka yang telah memiliki predisposisi pada penyakit ini. $^{2}$

Menurut WHO dalam Kemenkes RI, pada 2016 terdapat sekitar 35 juta orang terkena depresi, 60 juta orang terkena bipolar, 21 juta orang terkena skizofrenia, serta 47,5 juta terkena dimensia. $^{3}$ Data Riskesdas 2013 juga memunjukkan prevalensi gangguan jiwa berat, seperti skizofrenia mencapai sekitar 400.000 orang atau sebanyak 1,7 per 1.000 penduduk. ${ }^{4}$

Skizofrenia seperti penyakit kejiwaan lainnya memerlukaan waktu yang lama untuk pulih. Masalah utama pada pasien paska rawat inap adalah kepatuhan kontrol atau kepatuhan dalam minum obat. Faktor-faktor yang mempengaruhi ketidakpatuhan dapat digolongkan menjadi empat bagian yaitu individu atau pasien sendiri, dukungan dari keluarga, dukungan sosial dan juga dukungan dari petugas kesehatan, kepatuhan pasien dalam melakukan kontrol juga berpengaruh terhadap kejadian relaps. ${ }^{5}$ Hal yang dapat dilakukan untuk meningkatkan kepatuhan pasien antara lain menyederhanakan regimen, meningkatkan pengetahuan, memodifikasi keyakinan pasien, meningkatkan komunikasi dengan pasien, menghindari informasi yang bias, dan mengevaluasi kepatuhan. ${ }^{6}$

Pengetahuan merupakan faktor yang sangat penting untuk terbentuknya tindakan seseorang. Pengetahuan yang didasari dengan pemahaman yang tepat akan menumbuhkan perilaku baru yang diharapkan, khususnya kemandirian dalam melakukan perawatan gangguan jiwa terutama terkait dengan kepatuhan dalam pengobatan klien skizofrenia. Pengetahuan keluarga tentang kapan kontrol, dimana tempat kontrol, cara mendapatkan obat, memberikan obat sesuai dengan dosis dan mengikuti anjuran perawat dan petugas kesehatan lain. ${ }^{7}$
Kesembuhan pasien skizofrenia memerlukaan waktu yang lama untuk pulih, hal ini sangat dipengaruhi oleh keterlibatan terapi medis dan terapi psikologis yang sebagian besar dilakukan oleh anggota keluarga pada saat pasien di rumah. Dukungan keluarga dalam penanganan pasien skizofrenia memerlukan obat-obat antipsikotik yang efektif mengobati "gejala positif" pada episode akut dan mencegah kekambuhan. ${ }^{8}$

Kejadian skizofrenia di Provinsi Jambi mengalami peningkatan setiap tahun, diketahui bahwa skizofrenia merupakan penyakit terbanyak di unit rawat jalan rumah sakit jiwa, pada tahun 2015 sebanyak 4326 orang dan tahun 2016 menjadi 9565 orang atau meningkat $45 \%$. Tahun 2017 sebanyak 11877 orang atau meningkat $80 \%$ dibandingkan tahun sebelumnya. ${ }^{9}$ Hasil survey awal pada tanggal 6 Januari 2018 pada 6 orang keluarga pasien skizofrenia didapatkan hasil 4 orang keluarga pasien mengatakan rutin mengantarkan pasien untuk kontrol sesuai jadwal dan 2 orang diantaranya tidak selalu rutin

Menjaga kesehatan jiwa seluruh masyarakat Indonesia merupakan tugas semua pihak. Keluarga sebagai unit terkecil masyarakat harus mampu menjadi garda terdepan berperan dalam menjaga kesehatan jiwa anggota keluarganya dan menjadi pihak yang memberikan pertolongan pertama psikologis apabila tampak gejala-gejala yang mengarah pada masalah kesehatan jiwa. ${ }^{3}$

\section{METODE}

Penelitian ini adalah penelitian kuantitatif dengan pendekatan cross setional untuk mengetahui hubungan pengetahuan dan dukungan keluarga dengan kepatuhan kontrol pasien skizofrenia di Poli Jiwa RSJD Provinsi Jambi tahun 2018. Populasi dalam penelitian ini adalah seluruh keluarga pasien skizofrenia di Poli Jiwa RSJD Provinsi Jambi tahun 2017 sebanyak 11877 orang, dengan jumlah sampel 96 orang keluarga dari pasien yang melakukan kontrol yang dipilih secara accidental sampling. Instrumen penelitian yang digunakan berupa lembar ceklist kontrol ulang dan kuesioner tentang pengetahuan dan dukungan keluarga. Penelitian dilaksanakan pada bulan Juli 2018 di Poliklinik rawat jalan. Kepada responden dilakukan informed consent. Responden diminta mengisi kuisioner selama \pm 30 menit, dengan didampingi peneliti atau enumerator. Analisis data dilakukan secara univariat dan bivariat (ChiSquare). 


\section{HASIL DAN PEMBAHASAN}

Analisis hasil penelitian dilakukan secara univariat, untuk melihat distribusi frekuensi masing-masing variabel dan bivariat untuk mengetahui derajat kemaknaan dari masing-masing variabel. Adapun hasil penelitian dapat disampaikan pada tabel 1 .

Tabel 1. Distribusi Frekuensi Kepatuhan Kontrol Pasien Skizofrenia Di Poli Jiwa RSJD Provinsi Jambi Tahun 2018

\begin{tabular}{llll}
\hline No & $\begin{array}{l}\text { Kepatuhan } \\
\text { Kontrol }\end{array}$ & $\begin{array}{l}\text { Frekuensi } \\
(\mathbf{n})\end{array}$ & $\begin{array}{l}\text { Persentase } \\
(\%)\end{array}$ \\
\hline 1 & Tidak Patuh & 56 & 58.3 \\
\hline 2 & Patuh & 40 & 41.7 \\
\hline Total & $\mathbf{9 6}$ & $\mathbf{1 0 0 . 0}$ \\
\hline
\end{tabular}

Berdasarkan tabel 1 diketahui bahwa lebih dari sebagian yaitu 56 orang $(58,3 \%)$ tidak patuh melakukan kontrol.

Tabel 2. Distribusi Frekuensi Pengetahuan Pasien Skizofrenia Di Poli Jiwa RSJD Provinsi Jambi Tahun 2018

\begin{tabular}{llll}
\hline No & Pengetahuan & $\begin{array}{c}\text { Frekuensi } \\
(\mathbf{n})\end{array}$ & $\begin{array}{c}\text { Persentase } \\
(\%)\end{array}$ \\
\hline 1 & Kurang Baik & 48 & 50.0 \\
\hline 2 & Baik & 48 & 50.0 \\
\hline \multicolumn{2}{l}{ Total } & 96 & $\mathbf{1 0 0}$ \\
\hline
\end{tabular}

Berdasarkan tabel 2 diketahui bahwa pengetahuan responden jumlahnya seimbang.

Tabel 3. Distribusi Frekuensi Dukungan Keluarga Pasien Skizofrenia Di Poli Jiwa RSJD Provinsi Jambi Tahun 2018

\begin{tabular}{llll}
\hline No & $\begin{array}{l}\text { Dukungan } \\
\text { Keluarga }\end{array}$ & $\begin{array}{l}\text { Frekuensi } \\
(\mathbf{n})\end{array}$ & $\begin{array}{c}\text { Persentase } \\
(\mathbf{\%})\end{array}$ \\
\hline 1 & Negatif & 46 & 47.9 \\
\hline 2 & Positif & 50 & 52.1 \\
\hline \multicolumn{2}{l}{ Total } & $\mathbf{9 6}$ & $\mathbf{1 0 0}$ \\
\hline
\end{tabular}

Berdasarkan tabel 3 diketahui bahwa sebagian besar keluarga memberi dukungan positif yaitu sebanyak 50 orang $(52,1 \%)$.

Hasil hubungan pengetahuan keluarga dengan kepatuhan kontrol pasien skizofrenia di Poli Jiwa RSJD Provinsi Jambi tahun 2018 dapat dilihat pada tabel 4.

Berdasarkan tabel 4 diketahui dari 48 responden dengan pengetahuan kurang sebanyak 44 orang tidak patuh melakukan kontrol sedangkan 48 responden dengan pengetahuan baik sebanyak 36 orang patuh melakukan kontrol. Hasil uji statistik diperoleh nilai $p$-value
$=0.00<0,05$, hasil ini menunjukkan ada hubungan antara pengetahuan keluarga dengan kepatuhan kontrol pasien skizofrenia di Poli Jiwa RSJD Provinsi Jambi tahun 2018.

Tabel 4. Distribusi Hubungan Pengetahuan Keluarga Dengan Kepatuhan Kontrol Pasien Skizofrenia Di Poli Jiwa RSJD Provinsi Jambi Tahun 2018

\begin{tabular}{|c|c|c|c|c|c|c|c|}
\hline \multirow{3}{*}{$\begin{array}{c}\text { Pengeta } \\
\text { huan }\end{array}$} & \multicolumn{4}{|c|}{$\begin{array}{c}\text { Kepatuhan } \\
\text { kontrol }\end{array}$} & \multirow{2}{*}{\multicolumn{2}{|c|}{ Jumlah }} & \multirow{3}{*}{ p-value } \\
\hline & \multicolumn{2}{|c|}{$\begin{array}{l}\text { Tidak } \\
\text { Patuh }\end{array}$} & \multicolumn{2}{|c|}{ Patuh } & & & \\
\hline & $\mathbf{n}$ & $\%$ & $\mathrm{n}$ & $\%$ & $\mathbf{N}$ & $\%$ & \\
\hline $\begin{array}{l}\text { Kurang } \\
\text { Baik }\end{array}$ & 44 & 91,7 & 4 & 8,3 & 48 & 100 & 0.00 \\
\hline Baik & 12 & 25.0 & 36 & 75.0 & 48 & 100 & \\
\hline Total & 56 & 58,3 & 40 & 41,7 & 96 & 100 & \\
\hline
\end{tabular}

Tabel 5. Distribusi Hubungan Dukungan Keluarga Dengan Kepatuhan Kontrol Pasien Skizofrenia Di Poli Jiwa RSJD Provinsi Jambi Tahun 2018

\begin{tabular}{|c|c|c|c|c|c|c|c|}
\hline \multirow{3}{*}{$\begin{array}{c}\text { Dukungan } \\
\text { Keluarga }\end{array}$} & \multicolumn{4}{|c|}{$\begin{array}{c}\text { Kepatuhan } \\
\text { kontrol }\end{array}$} & \multirow{2}{*}{\multicolumn{2}{|c|}{ Jumlah }} & \multirow{3}{*}{ p-value } \\
\hline & \multicolumn{2}{|c|}{$\begin{array}{l}\text { Tidak } \\
\text { Patuh }\end{array}$} & \multicolumn{2}{|c|}{ Patuh } & & & \\
\hline & n & $\%$ & n & $\%$ & $\mathbf{N}$ & $\%$ & \\
\hline Negatif & 39 & 84,8 & 7 & 15,2 & 46 & 100 & 0.00 \\
\hline Positif & 17 & 34,0 & 33 & 66,0 & 50 & 100 & \\
\hline Total & 56 & 58,3 & 40 & 41,7 & 69 & 100 & \\
\hline
\end{tabular}

Berdasarkan tabel 5 diketahui dari 46 responden dengan dukungan keluarga negatif, sebanyak 39 orang tidak patuh melakukan kontrol sedangkan 50 responden dengan dukungan keluarga positif sebanyak 36 orang patuh melakukan kontrol. Hasil uji statistik diperoleh nilai $p$-value $=0.00<0,05$, hasil ini menunjukkan ada hubungan antara pengetahuan keluarga dengan kepatuhan kontrol pasien skizofrenia di Poli Jiwa RSJD Provinsi Jambi tahun 2018

Kepatuhan adalah sejauh mana perilaku pasien sesuai dengan ketentuan yang diberikan oleh profesional kesehatan. ${ }^{5}$ Kepatuhan yang dimaksud pada pasien, yaitu ketaatan dan kemauan yang baik dari pasien maupun keluarga pasien untuk selalu melakukan kontrol di poliklinik rumah sakit jiwa setiap bulan setelah pasien menjalani rawat inap. Kontrol rutin / perawatan jalan kesehatan perlu dilakukan oleh pasien agar tidak terjadi putus obat, dan para tenaga kesehatan juga dapat mengetahui perkembangan kesehatan pasien.

Hasil penelitian diketahui bahwa sebagian besar responden $(58,3 \%)$ tidak patuh melakukan kontrol dan $41,7 \%$ responden patuh 
dalam melakukan control. Pasien yang patuh berobat adalah yang menyelesaikan pengobatan secara teratur dan lengkap tanpa terputus selama minimal 6 bulan sampai dengan 9 bulan. Pasien lalai jika lebih dari 3 hari sampai 2 bulan dari tanggal perjanjian dan dikatakan dropout jika lebih dari 2 bulan berturut-turut tidak datang berobat setelah dikunjungi petugas kesehatan. ${ }^{10}$

Kepatuhan kontrol pasien skizofreania memerlukan adanya tingkat pengetahuan keluarga sehingga pasien mendapatkan terapi lebih dari keluarga yang mengakibatkan faktor kesembuhan pasien skizofrenia lebih cepat sembuh. ${ }^{11}$ Hasil uji statistik diperoleh nilai $p$ value $=0.00<0,05$, hasil ini menunjukkan ada hubungan antara pengetahuan keluarga dengan kepatuhan kontrol pasien skizofrenia di Poli Jiwa RSJD Provinsi Jambi tahun 2018. Hal ini juga sejalan dengan penelitian yang dilakukan Kosnandri, bahwa ada hubungan tingkat pengetahuan keluarga dengan kepatuhan pengobatan pada klien skizofrenia di Unit Rawat Jalan Rumah Sakit Jiwa Provinsi Jawa Barat tahun 2017 dengan $p$ value : $0,000<\alpha(0,05) .^{12}$

Pengetahuan merupakan faktor yang sangat penting untuk terbentuknya tindakan seseorang. Pengetahuan yang didasari dengan pemahaman yang tepat akan menumbuhkan perilaku baru yang diharapkan, khususnya kemandirian dalam melakukan perawatan gangguan jiwa terutama terkait dengan kepatuhan dalam pengobatan klien skizofrenia. Pengetahuan keluarga tentang kapan kontrol, dimana tempat kontrol, cara mendapatkan obat, memberikan obat sesuai dengan dosis dan mengikuti anjuran perawat dan petugas kesehatan lain. $^{7}$

Hasil penelitian menunjukan sebagian responden mempunyai pengetahuan yang kurang tentang pengobatan dan kontrol pasien skizofrenia menurut peneliti disebabkan oleh beberapa faktor di lapangan seperti minimnya pendidikan kesehatan dan informasi tentang perawatan skizofrenia oleh perawat sehingga keluarga tidak mendapatkan pengetahuan yang cukup sebagai bekal dalam merawat klien skizofrenia dirumah. Kebanyakan penyuluhan kesehatan dilakukan oleh mahasiswa praktikan. Faktor kedua yaitu kurangnya peran perawat dalam memaksimalkan keberadaan ruangan konseling untuk melakukan pendidikan kesehatan secara individual pada pasien dan keluarga.

Berdasarkan karakteristik diketahui bahwa sebagian responden memiliki pendidikan terakhir SD dan SMP yaitu sebanyak 45 orang (47\%). Salah satu faktor yang mempengaruhi pengetahuan adalah tingkat pendidikan. Maka semakin tinggi tingkat pendidikan yang ditempuh maka diharapkan pengetahuannya juga tinggi, dalam hal ini adalah pengetahuan keluarga tentang skizofrenia. Hal ini disebabkan karena kurangnya pemahaman responden dalam melakukan kontrol pada penderita skizofrenia. Norma subjektif kurang dan persepsi keluarga kurang baik juga menjadi pemicu kurangnya kepatuhan dalam melakukan kontrol pada penderita skizofrenia. ${ }^{1}$

Informasi yang masih dibutuhkan pasien adalah bahaya yang akan ditimbulkan jika tidak patuh melakukan kontrol. Untuk itu perlu diberikan penyuluhan yang lebih terinci pada saat kunjungan ulang, dan pada keluarga sebaiknya diberi buku khusus terkait penanganan pasien dirumah, tanda kambuh, waktu untuk melakukan kontrol ulang dan nomor yang bisa dihubungi jika keluarga mengalami hambatan dalam menangani pasien dirumah, dengan demikian interaksi antara petugas kesehatan dan keluarga dapat terjalin tanpa tatap mata dan diharapkan penanganan yang dilakukan merupakan hal yang tepat.

Hasil uji statistik diperoleh nilai $p$-value $=$ $0.00<0,05$ hasil uji ini menunjukkan ada hubungan antara dukungan keluarga dengan kepatuhan kontrol pasien skizofrenia di Poli Jiwa RSJD Provinsi Jambi tahun 2018. Penelitian ini sejalan dengan penelitian yang menunjukkan bahwa ada hubungan dukungan keluarga dengan kepatuhan kontrol berobat di Poliklinik Rumah Sakit Jiwa Daerah Dr. Amino Gondohutomo Semarang $(p$ value $=0,004) .{ }^{13}$

Berdasarkan hasil penelitian dukungan keluarga yang paling rendah dalam bentuk dukungan emosional, sementara dukungan emosional merupakan salah satu faktor yang menyebabkan kepatuhan. Hasil penelitian juga menggambarkan rata - rata pasien telah lebih dari 3 kali dirawat sehingga secara emosional keluarga sudah terbiasa dengan hal itu sehingga tidak menimbulkan kesedihan mendalam atau cemas untuk keluarga. Keluarga sudah mengetahui kalau tidak teratur dalam pengobatan dapat menimbulkan efek kekambuhan. ${ }^{14}$

Dukungan sosial keluarga yang buruk memberikan kontribusi untuk kambuh pada pasien skizofrenia. Seorang individu yang tidak memiliki dukungan keluarga atau sosial mungkin lebih cenderung kepada kegagalan pengobatan jika tidak diawasi, dukungan sosial yang baik juga memiliki efek perlindungan dalam membantu pasien untuk mengatasi stres situasi. Oleh karena itu penting bagi individu tersebut yang memiliki dukungan sosial yang kurang untuk memperoleh intervensi sosial, seperti partisipasi dalam kegiatan sosial Ketika pasien 
memiliki dukungan sosial yang buruk, tandatanda kambuh tidak terdeteksi secara dini sehingga mengarah ke kambuh yang parah. ${ }^{15}$

Pada penderita skizofrenia didapati adanya penurunan fungsi kognitif. Salah satu penurunan fungsi kognitif yang sering ditemukan adalah gangguan memori dan fungsi eksekutif lainnya. Fungsi eksekutif yang terganggu adalah kemampuan berbahasa, memecahkan masalah, mengambil keputusan, atensi dan perencanaan. Sedangkan gangguan memori yang sering dialami adalah gangguan memori segera dan memori jangka pendek yang dikenal sebagai memori kerja. ${ }^{16}$ Sehingga keluarga diharapkan memiliki kesabaran yang tinggi untuk mengingatkan dan mendorong pasien untuk terus melakukan perawatan di rumah dan melakukan kontrol ulang.

\section{KESIMPULAN DAN SARAN}

Berdasarkan hasil penelitian dapat disimpulkan bahwa sebanyak $48 \quad(50 \%)$ responden mempunyai pengetahuan kurang baik dan 50 responden $(52,1 \%)$ memiliki dukungan keluarga positif tentang kontrol ulang pasien skizofrenia di Poli Jiwa RSJD Provinsi Jambi. Ada hubungan antara pengetahuan keluarga dengan kepatuhan kontrol pasien skizofrenia di Poli Jiwa RSJD Provinsi Jambi tahun 2018 ( $p$ value $=0.00)$. Ada hubungan antara dukungan keluarga dengan kepatuhan kontrol pasien skizofrenia di Poli Jiwa RSJD Provinsi Jambi tahun 2018 ( $p$-value $=0.00)$.

Adapun saran yang diberikan adalah agar pihak rumah sakit khususnya perawat di Poli Jiwa dapat megoptimalkan pendidikan kesehatan pada saat pasien melakukan kunjungan ulang (kontrol) berupa penyuluhan rutin minimal sekali sebulan, sehingga pasien dapat mengidentifikasi tanda pasien akan kambuh atau cara menangani pasien saat pulang kerumah. Disamping itu sebaiknya pasien diberikan (leaflet) yang berisi informasi mengenai tanda dan cara penanganannya serta nomor yang bisa dihubungi jika pasien mengalami perburukan kondisi pada saat dirumah. Selanjutnya diharapkan agar penelitian ini dapat dikembangkan dalam pengabdian masyarakat dan juga menjadi dasar untuk penelitian lebih lanjut dengan desain dan variabel yang berbeda.

\section{UCAPAN TERIMAKASIH}

Ucapan terimakasih penulis sampaikan kepada Direktur dan Staf RSJD Propinsi Jambi yang telah memberikan izin menggunakan tempat dan pasien sehingga penelitian ini dapat terlaksana. Selanjutnya ucapan terimakasih juga penulis haturkan kepada Direktur Poltekkes Kemenkes Jambi.

\section{DAFTAR PUSTAKA}

1. Kaplan \& Sadock . Buku Ajar Psikiatri Klinis. Edisi 2. Jakarta: EGC. 2018

2. Yosep, I. Keperawatan Jiwa. Refika Aditama. Bandung. 2009

3. Kementrian Kesehatan Republik Indonesia. Peran keluarga dukung kesehatan jiwa masyarakat. 2016 [diakses tanggal 24 Mei 2018]. www.depkes.go.id.

4. Riskesdas. Angka Prevalensi Kesehatan Jiwa di Indonesia. Kemenkes. 2013

5. Niven. Psikologi Kesehatan : Pengantar Untuk Perawat Dan Tenaga Kesehatan Profesional Lain. Jakarta: EGC. 2012

6. Suharjo. Membangun Budaya Keselamatan Pasien dalam Praktek Kedokteran. Yogyakarta: Kanisius. 2008

7. Videbeck, Sheila L. Buku Ajar Keperawatan Jiwa, Jakarta: EGC. 2008

8. Katona, et al. At a Glance Psikiatri Edisi Keempat. Jakarta: Erlangga

9. Rekam Medis RSJD Provinsi Jambi, (2015-2017). Data Pasien Skizofrenia RSJD Provinsi Jambi. 2017

10. Kemenkes RI. Panduan Hari Kesehatan Jiwa Sedunia tahun 2011 The Great Push : Investing in Mental Health. Dirjen Bina Kesehatan Jiwa. Jakarta, 2011

11. Keliat, dkk. Model Praktik Kepera watan Profesional Jiwa. Jakarta: EGC. Poltekkes Jambi. 2010

12. Kosnandri. Hubungan Tingkat Pengetahuan Keluarga Dengan Kepatuhan Pengobatan Pada Klien Skizofrenia di Unit Rawat Jalan Rumah Sakit Jiwa Provinsi Jawa Barat Tahun 2017. Bandung. 2018. [diakses tanggal 3 Juni 2018] http://ejournal. stikesbhaktikencana.ac.id

13. Indirawati. R. Hubungan Antara Dukungan Keluarga dengan Kepatuhan Kontrol Berobat Pada Klien Skizofrenia di Rumah Sakit Jiwa Daerah Dr. Amino Gondohutomo Semarang. 2013. [diakses diakses tanggal 3 Juni 2018] http://ejournal. stikestelogorejo.ac.id.

14. Setiadi. Konsep dan Proses Keperawatan Keluarga. Yogyakarta: Graha Ilmu. 2008

15. Rao. Management Of Relapse In Schizophrenia. Consultant Psychiatrist, Early Psychosis Intervention Programme (EPIP), Institute of Mental Health, Singapore. 2013

16. Rudyanto. Skizofrenia \& Diagnosa Banding. Jakarta: FKUI. 2017 